\title{
OPTIMIZATION AND ANNUAL AVERAGE POWER PREDICTIONS OF A BACKWARD BENT DUCT BUOY OSCILLATING WATER COLUMN DEVICE USING THE WELLS TURBINE
}

\author{
Christopher Smith \\ Applied Research Laboratory \\ The Pennsylvania State University \\ University Park, PA, USA
}

Steven Willits

Applied Research Laboratory

The Pennsylvania State University

University Park, PA, USA

\author{
Diana Bull \\ Water Power Department \\ Sandia National Laboratories \\ Albuquerque, NM, USA
}

\author{
${ }^{1}$ Arnold Fontaine \\ Applied Research Laboratory \\ The Pennsylvania State University \\ University Park, PA, USA
}

${ }^{1}$ Corresponding author: aaf1@arl.psu.edu

\begin{abstract}
This paper presents work completed by The Applied Research Laboratory at The Pennsylvania State University, in conjunction with Sandia National Labs, on the optimization of the power conversion chain (PCC) design to maximize the Average Annual Electric Power (AAEP) output of an Oscillating Water Column (OWC) device. The design consists of two independent stages. First, the design of a floating OWC, a Backward Bent Duct Buoy (BBDB), and second the design of the PCC. The pneumatic power output of the BBDB in random waves is optimized through the use of a hydrodynamically coupled, linear, frequencydomain, performance model that links the oscillating structure to internal air-pressure fluctuations. The PCC optimization is centered on the selection and sizing of a Wells Turbine and electric power generation equipment. The optimization of the PCC involves the following variables: the type of Wells Turbine (fixed or variable pitched, with and without guide vanes), the radius of the turbine, the optimal vent pressure, and the sizing of the power electronics.
\end{abstract}

\section{INTRODUCTION}

Oscillating Water Column (OWC) devices are designed to capture the energy from ocean waves by converting pressure fluctuations in an enclosed air chamber into electricity for insertion into a local electric power grid. These pressure fluctuations are generated by incident waves exciting the free surface in a partially submerged structure with an opening. OWC's take several forms from fixed shoreline devices to floating buoys. The design of a deployable OWC device consists of two major parts: the design of the wave-to-pneumatic power converter, and the design of the pneumatic-to-electric power conversion equipment.

The wave-to-pneumatic converter is designed to capture the most available power from the incident waves. The pneumatic power is then converted to electrical power by use of an air turbine connected to an electric generator. The electricity produced is conditioned prior to insertion to the local power grid.

Many wave-to-pneumatic power performance models have been developed [1-7] for both grounded and floating OWC devices. OWCs require the pressure distribution on the internal free surface to be modeled which, when employing linear potential flow theory, requires calculation of the diffraction and radiation potentials for the free surface or at least an approximation of these [6-7]. The full mathematical formulation of the performance model employed in this paper was first presented in [5].

Many studies [8-11] have evaluated the effects of the pneumatic-to-electric power conversion equipment on the power output of OWC devices. There are multiple options for the primary converter which takes the incident pneumatic power and turns it into mechanical power: Wells Turbine (fixed or variable pitched), impulse turbine, a Denniss-Auld turbine or a radial turbine. The differences between these 
turbines relate to their pressure-flow relationships, peak and bandwidth efficiencies, and their directional rectification.

The Wells Turbine possess' a linear relationship between pressure and flow. Since the performance model is limited to linear systems, the only primary converter considered in this paper is the self-rectifying Wells Turbine. This turbine choice in no longer predominant in industry since the peak value and bandwidth of the efficiency is known to be inferior to other turbines [11].

Much research has been conducted on understanding the flows through Wells type turbines due to their simplicity and past use. Gato and Falcão [12], along with Raghunathan [13] provide thorough introductions into the theory of the Wells turbine. These authors, and others [1316] have shown that the Wells turbine operates at peak efficiency for a relatively narrow range of flow coefficients. Obtaining optimum flow coefficients can be achieved by using chamber pressure relief valves and by controlling the turbine RPM for a fixed turbine diameter. BritoMelo, et. al. and Falcão \& Justino [1, 16] have shown that the use of pressure relief, or flow control, valves can increase the average power converted to electricity by maintaining flow conditions near the peak efficiency of the turbine.

In support of the DOE sponsored Reference Model Project ${ }^{1}$, this paper investigates the optimization of a PCC for the BBDB. The BBBD performance model optimizes the pneumatic power available to the PCC. The pneumatic power is represented by the RMS pressure and volume flow rate predictions for each sea state in the wave climate. The PCC optimization then uses the sea state RMS values in combination with experimental Wells Turbine efficiency values to optimally size the turbine, generator, Variable Frequency Drive (VFD), and downstream power electronics. The pneumatic power is then decremented by the Wells Turbine, generator, VFD, and power electronic efficiencies for each sea state. Since the RMS pressure and flow are used, this method applies only one efficiency value for the Wells Turbine in a given sea state regardless of the fact that a given sea state contains a distribution of pressure and flow values. This methodology is repeated for a range of sea states assuming this single parameter representation as opposed to a full stochastic analysis as seen in [8]. The Average Annual Electric Power (AAEP) is then calculated based on the Joint Probability Distribution (JPD) of those sea states.

\footnotetext{
1 See http://energy.sandia.gov/?page_id=16794
}

\section{BBDB PERFORMANCE MODELLING IN RANDOM WAVES}

The linear, frequency-domain performance model that links the oscillating structure to airpressure fluctuations with a Wells Turbine in 3dimensions described in [5] is used in this paper. The dynamics of the floating structure and the internal pressure distribution are modeled using WAMIT v6.4, a Boundary Element Method (BEM) solver. The hydrodynamic parameters are found for wave frequencies spanning 0 to $2.5 \mathrm{rad} / \mathrm{s}$ in $0.01 \mathrm{rad} / \mathrm{s}$ intervals assuming infinite depth. An array of 231 field points defining the interior free surface allows hydrodynamic parameters relating to the fluctuating air-pressure within the OWC to be calculated using reciprocity relations. [5]

The coupled governing equations in response to wave amplitude $A$ are given in matrix notation by:

$$
\left(\begin{array}{l}
\boldsymbol{f} \\
q
\end{array}\right) A=\left(\begin{array}{cc}
\boldsymbol{Z}_{i} & -\boldsymbol{H}_{i} \\
\boldsymbol{H}_{i}^{T} & Y_{i}+\frac{1}{R_{\text {load }}}
\end{array}\right)\left(\begin{array}{l}
\boldsymbol{u} \\
p
\end{array}\right)
$$

where bold quantities are matrices or column vectors. Equation 1 shows that the velocity Response Amplitude Operator (RAO), the velocity of the body per unit wave amplitude $\left(\boldsymbol{u} /{ }_{A}\right)$ for each incident wave frequency, is united to the internal pressure $(p)$ RAO through hydrodynamic coupling $\boldsymbol{H}_{i}$ and the control term $R_{\text {load }}$. Physically, this control term $R_{\text {load }}$ represents the linear slope between pressure and flow of the Wells turbine. The velocity RAO is also dependent upon the total radiation impedance, $\boldsymbol{Z}_{i}$, and the excitation force $\boldsymbol{f}$. The total radiation impedance includes: linearized viscous losses, restoring forces, and mooring forces from the design presented in [17]. The pressure RAO is additionally dependent upon the total radiation admittance, $Y_{i}$, and the excitation volume flow $q$. The total radiation admittance includes the effects of linearized isentropic air compressibility and linearized viscous losses. Further detail on these terms can be found in [5].

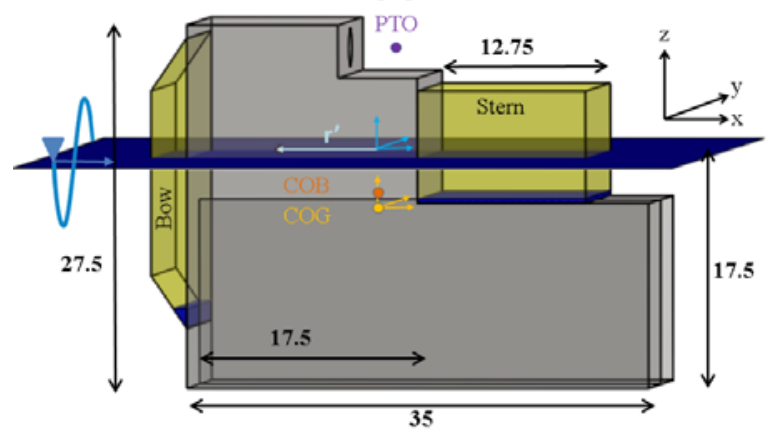

FIGURE 1. MODEL OF THE BBDB 


\begin{tabular}{|c|c|c|c|c|c|c|c|c|c|c|c|c|c|c|c|c|}
\hline & \multicolumn{15}{|c|}{ Peak Period, Tp [sec] } \\
\hline & & 4.7 & 5.7 & 6.7 & 7.7 & 8.7 & 9.7 & \begin{tabular}{|l|l|l}
$\mid 10.7$ & $-r \cdot r$ \\
\end{tabular} & 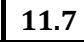 & $\mid \mathbf{1 2 . 7}$ & $\mid 13.7$ & 14.7 & \begin{tabular}{|l|l}
$\mid 15.7$ &
\end{tabular} & $\mid 16.7$ & $\mid \mathbf{1 7 . 7}$ & 18.7 \\
\hline \multirow{12}{*}{ 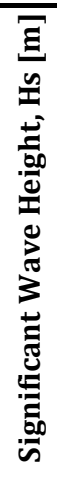 } & 0.25 & 0.0 & 0.0 & 0.0 & 0.0 & 0.0 & 0.0 & 0.0 & 0.0 & 0.0 & 0.0 & 0.0 & 0.0 & 0.0 & 0.0 & 0.0 \\
\hline & 0.75 & 0.0 & 0.004 & 0.011 & 0.011 & 0.013 & 0.004 & 0.006 & 0.003 & 0.0 & 0.0 & 0.003 & 0.004 & 0.005 & 0.0 & 0.0 \\
\hline & 1.25 & 0.0 & 0.010 & 0.028 & 0.024 & 0.046 & 0.018 & 0.022 & 0.011 & 0.009 & 0.007 & 0.005 & 0.004 & 0.004 & 0.002 & 0.0 \\
\hline & 1.75 & 0.0 & 0.002 & 0.025 & 0.027 & 0.036 & 0.021 & 0.035 & 0.019 & 0.014 & 0.012 & 0.010 & 0.005 & 0.005 & 0.003 & 0.0 \\
\hline & 2.25 & 0.0 & 0.0 & 0.006 & 0.023 & 0.036 & 0.017 & 0.033 & 0.024 & 0.019 & 0.015 & 0.010 & 0.006 & 0.005 & 0.003 & 0.0 \\
\hline & 2.75 & $\overline{0.0}$ & 0.0 & 0.0 & 0.009 & \begin{tabular}{|l}
0.027 \\
\end{tabular} & 0.010 & 0.022 & 0.020 & 0.015 & 0.013 & 0.009 & 0.005 & 0.005 & 0.003 & 0.0 \\
\hline & 3.25 & 0.0 & 0.0 & 0.0 & 0.0 & 0.011 & 0.007 & 0.012 & 0.013 & 0.012 & 0.011 & 0.008 & 0.005 & 0.004 & \begin{tabular}{|l|}
0.0 \\
\end{tabular} & 0.0 \\
\hline & 3.75 & 0.0 & 0.0 & 0.0 & 0.0 & 0.003 & 0.003 & 0.005 & \begin{tabular}{|l}
0.007 \\
\end{tabular} & 0.007 & 0.007 & \begin{tabular}{|l}
0.006 \\
\end{tabular} & 0.003 & 0.003 & 0.0 & 0.0 \\
\hline & 4.25 & 0.0 & 0.0 & 0.0 & 0.0 & 0.0 & 0.0 & 0.0 & 0.003 & 0.003 & 0.004 & 0.004 & 0.0 & 0.002 & 0.0 & 0.0 \\
\hline & 4.75 & 0.0 & 0.0 & 0.0 & 0.0 & 0.0 & 0.0 & 0.0 & 0.0 & \begin{tabular}{|l|}
0.0 \\
\end{tabular} & \begin{tabular}{|l|}
0.0 \\
\end{tabular} & 0.002 & 0.0 & 0.0 & 0.0 & 0.0 \\
\hline & 5.25 & 0.0 & 0.0 & 0.0 & 0.0 & 0.0 & 0.0 & 0.0 & 0.0 & 0.0 & 0.0 & 0.0 & 0.0 & 0.0 & 0.0 & 0.0 \\
\hline & & 4.0 & 4.9 & 5.7 & 6.6 & 7.5 & 8.3 & 9.2 & 10.0 & 10.9 & 11.7 & 12.6 & 13.5 & 14.3 & 15.2 & 16.0 \\
\hline
\end{tabular}

FIGURE 2. JPD FOR NDBC 46212 NEAR EUREKA CA.

\section{BBDB Geometry}

The geometry of the BBDB is the same as that described more fully in [5]. Figure 1 illustrates the structural design and highlights key dimensions. This design is not optimized to reduce viscous losses or encourage weathervanning.

\section{Northern California Deployment Location}

The deployment site is approximately $3 \mathrm{nmi}$ from shore on a $60 \mathrm{~m}$ depth contour off the northern California coast near Eureka. Archived summary statistics from National Data Buoy Center (NDBC) 46212 buoy were used to generate a JPD of significant wave height, $H_{s}$, with peak period, $T_{p}$ [18]. The JPD characterizes the probability of a particular sea state occurring. This description of the deployment climate is generated from many years of data and is used to understand the long-term characteristics of a climate whereas a wave spectrum, $S(\omega)$, is used to understand the short term characteristics of a sea state.

The NDBC data buoy is located in $40 \mathrm{~m}$ of water depth. Summary statistics spanning seven years (2004-2011) were used for this analysis. Figure 2 shows the 46212 JPD; the sum of all values within the JPD is one. The JPD is presented such that important aspects of the deployment climate may be quickly assessed: $95 \%$ of the climate is contained within the pink boxes, while $75 \%$ and $50 \%$ are contained within the yellow and green boxes respectively, the red highlighted values indicate the most common period for each $H_{s}$ and the bolded red value indicates the most likely wave.

It is assumed in this analysis that the waves are unidirectional. Since the BBDB is directionally dependent, this assumption likely overestimates the pneumatic and electric power. However, assuming unidirectional waves allows the primary driver of the device performance, the frequency- dependence, to be effectually captured. A Bretschneider spectral shape is assumed for this Northern CA deployment.

\section{BBDB Spectral Analysis}

The monochromatic BBBD performance model presented in [5] is expanded into a spectral model for this analysis. This spectral model is optimized through the selection of $R_{\text {load }}$ to create the maximal pneumatic power available to the PCC for a given sea state.

The linear response of a device in the shortterm will be governed by the wave spectrum describing the particular sea state. Since the response of the device is linear, the spectral response will be stationary and random following a Gaussian distribution, just as the wave spectrum does, thus allowing for traditional spectral moment analysis [19].

The monochromatic response of the device is given by RAOs for any variable of interest. The RAOs are derived according to Equation 1 for a constant $R_{\text {load }}$ across all frequencies. The variable response spectrum, $S_{R}$, for any variable can then be obtained through Equation 2

$$
S_{R}(\omega)=[\operatorname{RAO}(\omega)]^{2} S(\omega) .
$$

Using spectral moment analysis, the root-meansquare (RMS), as shown in Equation 3, can be calculated for any variable, $R$.

$$
R_{R M S}=\sqrt{\int S_{R}(\omega) d \omega}=\sqrt{m_{0}}
$$

Above, $m_{0}$ is the zeroth moment of the spectral density. The integral in Equation 3 is approximated using trapezoidal summation over the frequency range defined by the WAMIT run.

The optimal variable response is controlled by the selection of $R_{\text {load }}$. However, unlike the analysis of monochromatic waves, there is no 
closed form optimization procedure for $R_{\text {load }}$ when evaluating the spectral response. Hence the optimal $R_{\text {load }}$ for each sea state is found through numeric optimization. Figure 3 shows the optimal $R_{\text {load }}$ for each peak period in the JPD.

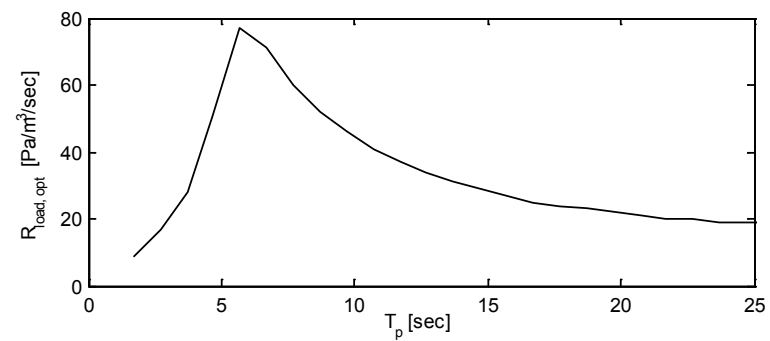

FIGURE 3. OPTIMAL RLOAD FOR TP.

The average pneumatic power $P$ absorbed in sea state $i=T_{p}, j=H_{s}$ can be calculated using Equation 4 below.

$$
\left\langle P_{i j}\right\rangle=R_{\text {load }, i} \int \mathrm{Q}_{T, i j}(\omega)^{2} S_{i j}(\omega) d \omega,
$$

where the optimal resistive load is only a function of the peak period $i$ as shown in Figure 3 , and $Q_{T}$ is the total volume flow. The optimal pneumatic power found through the above procedure does not account for the Wells Turbine efficiencies. It is expected that accounting for the Wells Turbine efficiencies in a spectral manner would result in a distinct $R_{\text {load }}$ profile. This paper has performed full spectral analysis only for the pneumatic estimates. As shown in [8], the spectral analysis could have been completed all the way through the mechanical and electrical power calculations.

\section{ELECTRICITY GENERATION EQUIPMENT DESIGN AND PERFORMANCE}

The Wells air turbine is a power extraction device capable of collecting power in a bidirectional flow. It has the potential for use in OWC devices due to the bi-directional nature of the flow in such devices. The Wells turbine consists of a fixed number of blades, which typically have a symmetric airfoil profile, and which have the blade chord oriented perpendicular to the rotational axis of the rotor.

\section{Wells Turbine Performance}

The performance of the Wells turbine depends on the specific design of the turbine blades and any other features, such as variable pitch blades or the use of guide vanes. Performance data is typically collected on small scale versions of the Wells turbine and is reported as the non-dimensional pressure head coefficient $\psi$ and the turbine efficiency $\eta$ versus the nondimensional flow coefficient $\phi$. The efficiency versus flow coefficient curves for the various turbine designs used in the present studies are shown in Figure $4[1,14,20]$ where $\phi$ is defined by Equation 5 .

$$
\phi=\frac{U}{\omega R}=\frac{Q_{T}}{\frac{\pi^{2}}{4} D^{3} n}
$$

Where $U$ is mean axial velocity, $\omega$ is the turbine rotational speed in $\mathrm{rad} / \mathrm{s}, \mathrm{R}$ is the turbine tip radius, $Q_{T}$ is the volumetric flow rate through the turbine, $\mathrm{D}$ is the turbine tip diameter, and $\mathrm{n}$ is the turbine rotational speed in rev/s. Notice that peak efficiency for fixed pitch type turbines is larger than for variable pitch type turbines. However, peak efficiency comes at the cost of efficiency bandwidth across $\phi$. Varying the turbine pitch allows the turbine to adapt to a wide range of flow coefficients, which accounts for the increased efficiency bandwidth. The shift in the efficiency curve for the variable pitch turbine is a result of the test turbine in [20] acting as a fan for lower flow coefficients.

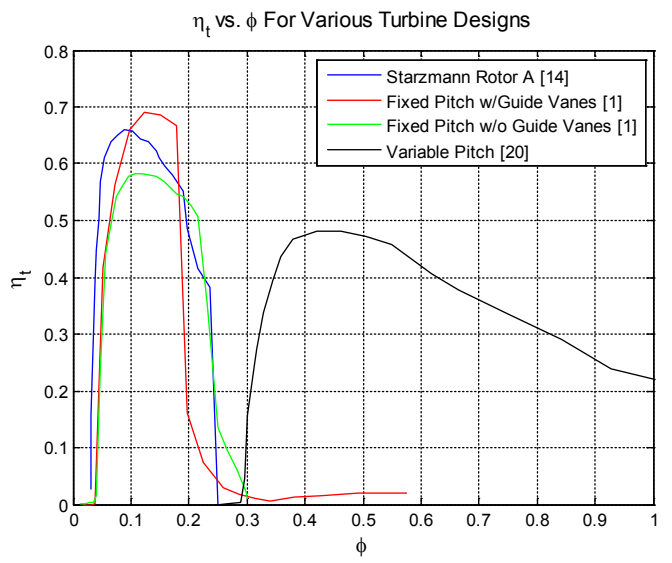

FIGURE 4. WELLS TURBINE EFFICIENCY VS. FLOW COEFFICIENT FOR VARIOUS TURBINE DESIGNS.

Brito-Melo, et. al. [1] suggest that the use of a pressure relief valve for flow control is able to maintain flow coefficients near the point of peak efficiency. Another method for maintaining flow coefficients near the peak efficiency value is by variation of the turbine rotational speed.

Another facet of the Wells turbine is that for a single RPM and tip diameter the relationship between $\phi$ and $\psi$ is approximately linear. This is verified in Figure 5 from [14]. The non-linear portion of Figure 5 is caused by aerodynamic stalling due to large flow incidence angles and the effects of compressibility on the rotor blades.

The current work does not attempt to address the effects of Reynolds number or Mach number on the rotor blades; this nonlinearity will have a detrimental effect if the design does not put rotational speed limitations on the turbine [13]. As a result, the AAEP predictions presented herein are considered ideal. Future work should include 
effects of compressibility on the turbine performance in the BBDB stochastic model.

$\psi$ vs. $\phi$ For Starzmann Rotor A [1]

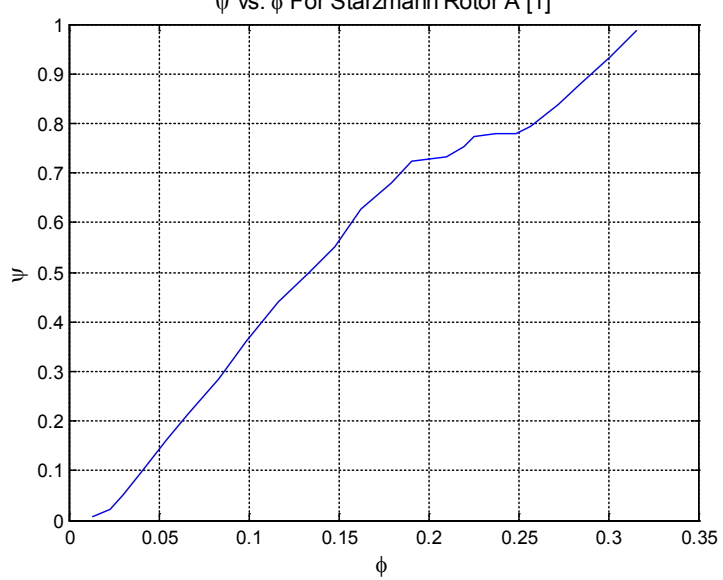

FIGURE 5. $\Psi$ VS. $\Phi$ FOR STARZMANN ROTOR A [1], TYPICAL FOR OTHER TURBINE DESIGNS USED IN THE CURRENT STUDIES.

\section{Average Annual Electric Power Predictions}

Using the BBDB RMS internal pressure and the optimal $R_{\text {load }}$ shown in Figure 3 , the volumetric flow rate through the turbine can be found according to Equation 6, where $p$ is the RMS dimensional chamber pressure and $\rho$ is the density of air at sea level conditions.

$$
R_{\text {load }}=\frac{p}{Q_{T}}=\frac{\psi}{\phi} \frac{n \rho}{R}
$$

In order to achieve varying $R_{\text {load }}$ values for a fixed turbine radius the rotational speed of the turbine must vary. Varying the turbine RPM will change the non-dimensional flow coefficient in the turbine, which could result in operating at nonpeak turbine efficiencies. The turbine RPM required to achieve the optimum $R_{\text {load }}$ is found using Equation 7. It is assumed that rotational speed is a constant for each individual sea state, that rotational speed changes between sea states, and oscillations in rotational speed as a result of inertial storage in the Wells Turbine are small.

$$
n=\frac{\phi}{\psi} \frac{R}{\rho} R_{\text {load }}
$$

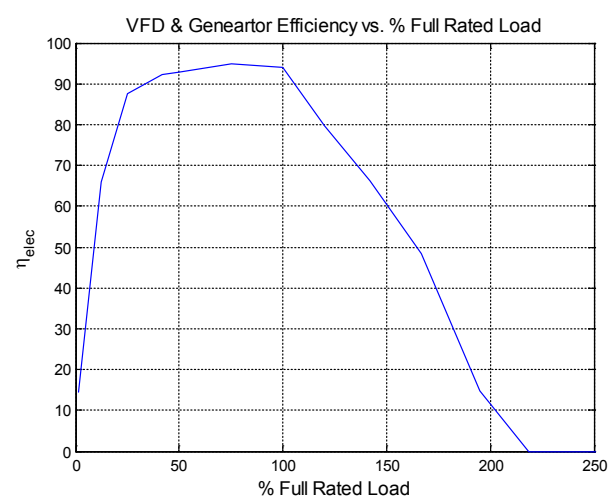

FIGURE 6. COMBINED VFD AND GENERATOR EFFICIENCY VS. \% FULL RATED LOAD OF ELECTRICITY GENERATION EQUIPMENT.

With the RPM calculated and turbine radius known the non-dimensional flow coefficient can be determined according to Equation 5. This is then used to look up turbine efficiency, $\eta_{t}$, based on small scale test data from Figure 4. Usage of efficiency data from these small scale experiments neglects the effects of Reynolds and Mach numbers. With $\eta_{\mathrm{t}}$ known, the mechanical power, $M_{i j}$, available to the electricity generation equipment for each sea state is found using Equation 8,

$$
M_{i j}=p_{R M S_{i j}} Q_{T, R M S_{i j}} \eta_{t} .
$$

The total efficiency of the electricity generation equipment is $\eta_{\text {elec }}=\eta_{\text {gen }} \eta_{V F D} \eta_{\text {Powercond }}$. However in this work, only the generator and VFD efficiencies are considered. Once the turbine mechanical power is known, $\eta_{\text {gen }}$ and $\eta_{\text {VFD }}$ are found from typical generator and VFD efficiency curves [21,22], which then allows the calculation of $\eta_{\text {elec. }}$ Figure 6 shows an $\eta_{\text {elec }}$ curve if the VFD and generator have the same power rating. Once $\eta_{\text {elec }}$ is known the electric power, $W_{i j}$, generated by the system in each sea state is then found using Equation 9.

$$
W_{i j}=M_{i j} \eta_{\text {elec }}
$$

Annual Average Electric Power (AAEP) is then found using Equation 10, where JPD is the joint probability distribution of a sea state, $n$ is the index of the largest peak period of the sea state matrix, and $m$ is the index of the largest significant wave height of the sea state matrix.

$$
A A E P=\sum_{i, j=1}^{i=n, j=m} W_{i j}(J P D)_{i j}
$$

\section{DESIGN STUDIES}

\section{Methodology}

The methodology followed for determining the optimum turbine tip radius, vent pressure, VFD power rating and electric generator power rating in the design studies is as follows:

1. Select a turbine type from the types indicated in Figure 4.

2. Specify a single tip radius, vent pressure, VFD power rating and electric generator rating.

3. Based on the required $R_{\text {load }}$ for each sea state, calculate the rotational speed of the Wells Turbine for each sea state.

4. Calculate the flow coefficient for each sea state.

5. Find $\eta_{\mathrm{t}}$ and calculate mechanical power, $M$, for each sea state. 
6. Use $M$ and the power ratings of the VFD and the generator to determine $\eta_{\text {elec }}$.

7. Calculate the electric power, $W$, generated for each sea state.

8. Determine the AAEP for the turbine design, and electricity generation equipment combination.

9. Loop through all desired tip radii, vent pressures, VFD power ratings, and electric generator ratings.

10.Plot and analyze results to determine design with largest AAEP.

This methodology has been implemented using MATLAB for the following optimization studies.

Starzmann [14] provides a Wells turbine design methodology for a single pneumatic power $\left(p_{i j}, Q_{T_{i j}}\right)$, turbine damping $\left(R_{\text {load }}\right)$, turbine solidity and hub-to-tip ratio. The methodology uses design charts from experimental data for single stage, fixed pitch, Wells turbine without guide vanes. From the design charts the designer is able to calculate a turbine tip diameter and rotational speed for either the optimum operating point or the maximum operating point expected for the desired sea condition. Thus, in this procedure, the designer only uses one sea condition to determine the optimal turbine specifications.

The methodology presented in this paper selects the optimal turbine type, turbine tip radius, vent pressure, and power electronics based on the average annual performance for the entire wave climate at a specific location. Instead of calculating a single turbine size using design charts from the expected power output of the turbine for a single sea condition, AAEP is calculated for each PCC design across a range in the present methodology. Then the PCC design which produced the largest AAEP is selected as the optimum design for the entire wave climate. In this way the designer is able to accommodate the full complexity of the deployment climate in the Wells turbine and power electronics selection.

Below, design studies highlighting results from the design methodology will be discussed.

\section{Turbine Type Study}

Figure 4 shows $\eta$ versus $\phi$ for four different types of Wells turbine. Starzmann's Rotor A is a fixed pitch rotor, using a NACA 0021 profile at the blade base, a NACA 0018 profile at the blade midspan, a NACA 0015 profile at the blade tip, and with varying chord length along the blade span. The other types of turbines use a rotor design similar to that used by the PICO plant at the Azores, Portugal and include a fixed pitch rotor with guide vanes, the same fixed pitch rotor without guide vanes, and a variable pitch rotor $[1,14,20]$.

Table 1 shows AAEP and Significant Average Annual Power (SAEP) predictions, optimum, turbine tip radius, and optimum vent pressure for the four different types of turbine using a VFD Power rating of $373 \mathrm{~kW}$ and a generator power rating of $298 \mathrm{~kW}$. Starzmann's Rotor A achieves the largest AAEP, due to the relatively high, and broad (relative to the other fixed pitch turbines), efficiency curve. Thus the remainder of the studies will use the Starzmann Rotor A, and will focus on the effects of the other design variables.

TABLE 1. AAEP, SAEP, OPTIMUM TURBINE TIP RADIUS, AND VENT PRESSURE FOR DIFFERENT TYPES OF WELLS TURBINES.

\begin{tabular}{|c|c|c|c|c|}
\hline $\begin{array}{c}\text { Turbine } \\
\text { Type }\end{array}$ & $\begin{array}{c}\text { AAEP } \\
(\mathrm{kW})\end{array}$ & $\begin{array}{c}\text { SAEP } \\
(\mathrm{kW})\end{array}$ & $\begin{array}{c}\text { Optimum } \\
\text { Turbine } \\
\text { Tip Radius } \\
(\mathrm{m})\end{array}$ & $\begin{array}{c}\text { Vent } \\
\text { Pressure } \\
(\mathrm{Pa})\end{array}$ \\
\hline Starzmann A & 103.3 & 229.3 & 1.588 & 5380 \\
\hline Fixed Pitch & 74.1 & 182.2 & 0.923 & 6205 \\
\hline $\begin{array}{c}\text { Fixed Pitch } \\
\text { w/Vanes }\end{array}$ & 71.6 & 172.1 & 0.987 & 5875 \\
\hline $\begin{array}{c}\text { Variable } \\
\text { Pitch }\end{array}$ & 54.7 & 152.8 & 1.018 & 7525 \\
\hline
\end{tabular}

The variable pitch turbine does not perform as well as the fixed pitch turbines. This is due to the use of a pressure relief valve for flow control and the treatment of the turbine efficiency as a single value for each sea state, as opposed to spectrally.

\section{Turbine Tip Radius and Vent Pressure Studies}

Turbine tip radius was varied between 0.1 and $2 \mathrm{~m}$, vent pressure was varied between 100 and 10,000 $\mathrm{Pa}$, while the VFD and generator power ratings were set to $149 \mathrm{~kW}$. Application of the above methodology, using Starzmann's rotor A [14], produced a peak AAEP of $82.92 \mathrm{~kW}$ at a tip radius of $1.49 \mathrm{~m}$ and a vent pressure of $3730 \mathrm{~Pa}$. Figure 7 shows a contour plot of the AAEP at all of the tip radii and vent pressure combinations. This figure shows the optimum turbine tip radius at the peak AAEP. The optimum vent pressure was selected at the peak SAEP across the range of vent pressures for the optimum turbine tip radius.

Figures $7 \& 8$ show that above a certain vent pressure the AAEP is no longer dependent upon vent pressure, for a given turbine tip radius. This is because the flow coefficients for the most probable sea states, which are the ones predominantly contributing to power production, cease to be affected by the increasing vent pressure. 
Effects of VFD and Generator Rating on AAEP

Table 2 outlines the effects of varying the VFD and generator power rating using Starzmann's Rotor A [14]. It is important to note that while a generator can maintain high efficiency values when overloaded, the VFD can only output power up to its power rating. As a result any excess power put into the VFD is dumped out of the system, causing a steep decline in efficiency when the VFD is overloaded.

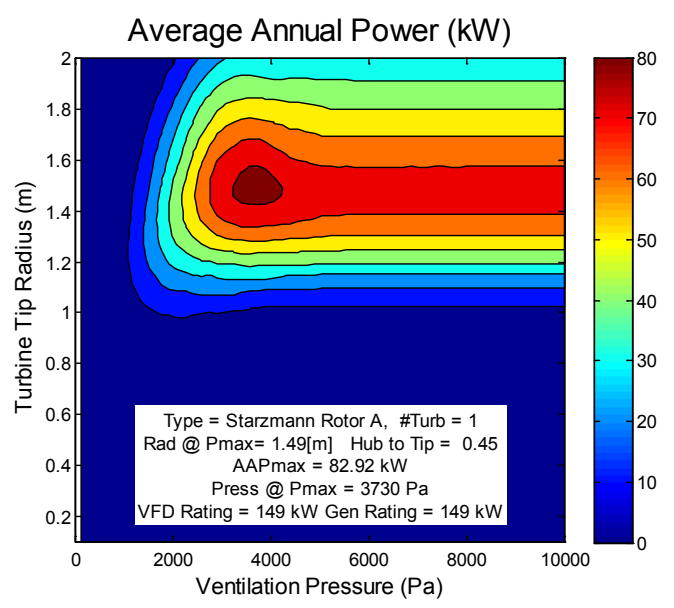

FIGURE 7. AAEP PREDICTIONS FOR VFD RATING OF 149 KW AND A GENERATOR RATING OF 149 KW, USING STARZMANN'S ROTOR A.

From the results in Table 2 AAEP is maximized for a VFD/generator power rating ratio of 1.25 for the wave climate and BBDB used in these studies. Further increases of the VFD/generator power rating ratio over-rates the electricity generation equipment causing losses in efficiency, see Figure 6. Under-rating of the VFD or generator also causes the same, or greater, losses. Increasing the VFD or generator rating also allows for an increase in the vent pressure and an increase in turbine tip radius, up to the VFD generator rating ratio of approximately 1.25. Larger vent pressures and tip radii can lead to increases in AAEP if the flow coefficients through the turbine remain near peak efficiency.

TABLE 2. AAEP PREDICTIONS FOR VARIOUS GENERATOR AND VFD POWER RATINGS.

\begin{tabular}{|c|c|c|c|c|c|}
\hline \multicolumn{5}{|c|}{ Annual Average Power (kW) } \\
\cline { 1 - 4 } VFD Rating (kW) & $\mathbf{7 5}$ & $\mathbf{1 4 9}$ & $\mathbf{2 2 4}$ & $\mathbf{2 9 8}$ & $\mathbf{3 7 3}$ \\
\hline $\mathbf{7 5}$ & 52.7 & 54.5 & 53.9 & 52.8 & 51.8 \\
\hline $\mathbf{1 4 9}$ & 63.7 & 82.9 & 83.3 & 82.5 & 81.4 \\
\hline $\mathbf{2 2 4}$ & 62.7 & 91.7 & 96.6 & 96.3 & 95.5 \\
\hline $\mathbf{2 9 8}$ & 61.9 & 91.9 & 101.3 & 101.7 & 101.0 \\
\hline $\mathbf{3 7 3}$ & 60.8 & 90.9 & 101.6 & 103.3 & 102.7 \\
\hline $\mathbf{4 4 7}$ & 59.1 & 89.8 & 100.6 & 103.0 & 102.7 \\
\hline $\mathbf{5 2 2}$ & 57.5 & 88.8 & 99.6 & 102.3 & 102.2 \\
\hline $\mathbf{5 9 7}$ & 55.7 & 87.9 & 98.7 & 101.3 & 101.3 \\
\hline $\mathbf{6 7 1}$ & 54.2 & 86.6 & 97.5 & 100.1 & 100.2 \\
\hline $\mathbf{7 4 6}$ & 53.0 & 85.4 & 96.3 & 99.0 & 99.0 \\
\hline
\end{tabular}

Figure 8 shows that as the generator rating increases toward a VFD Rating/Generator Rating ratio of 1.25 the losses incurred by under rating the electricity generation equipment are reduced. At higher VFD/generator rating ratios large AAEP losses occur at lower vent pressures because the energy captured by the BBDB overloads the generator enough to cause efficiency decrements. Once the VFD/generator rating ratio reaches approximately 1.25 the AAEP ceases to be a function of the vent pressure. As a result the optimum vent pressure is selected to be at the maximum SAEP, if the VFD/generator power rating ratio is greater than 1.25. Figure 8 also shows that the optimum vent pressure (and subsequently the turbine tip radius and the AAEP) is limited by the power rating of the generator.

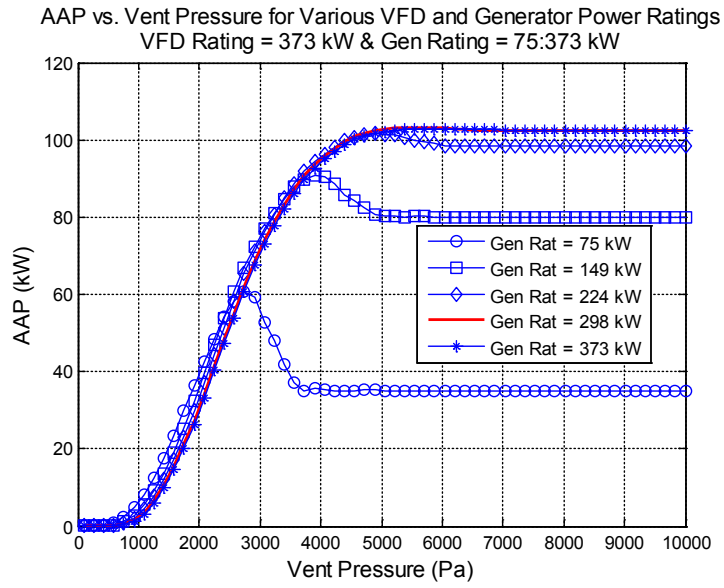

FIGURE 8. AAEP VS VENT PRESSURE FOR A RANGE OF GENERATOR POWER RATINGS AT A VFD POWER RATING OF 373 KW.

\section{Design Methodology Discussion}

The trends shown in Table 2 can be further understood by examination of the mechanical power entering the electricity generation equipment over the range of sea states. Figure 9 gives the mechanical power at the most probable sea states for a VFD power rating of $224 \mathrm{~kW}$, a generator power rating of $149 \mathrm{~kW}$, a vent pressure of $3895 \mathrm{~Pa}$ and a turbine tip radius of $1.53 \mathrm{~m}$. Mechanical power becomes constant as significant 
wave height increases due to the vent pressure limiting power captured by the BBDB. Also, at large wave heights and long wave periods the mechanical power drops to zero because the turbine flow coefficients in this region are too large and cause the turbine efficiency to be zero. It is evident in Figure 9 that the generator is under-rated for the high energy density sea states, although the VFD is rated properly for those sea states. The under-rating of the generator pushes the vent pressure and turbine tip radius lower even though the VFD power rating is satisfactory for the matrix of sea states. The low vent pressure and turbine tip radius reduces the overall energy captured by the BBDB causing a significant decrease in AAEP.

RMS Mechanical Power Data [kW], VentP = 3895 Pa, Rtip = 1.53 m, VFD Rating = 224 kW, Gen Rating 149 kW

Peak Period, Tp [sec]

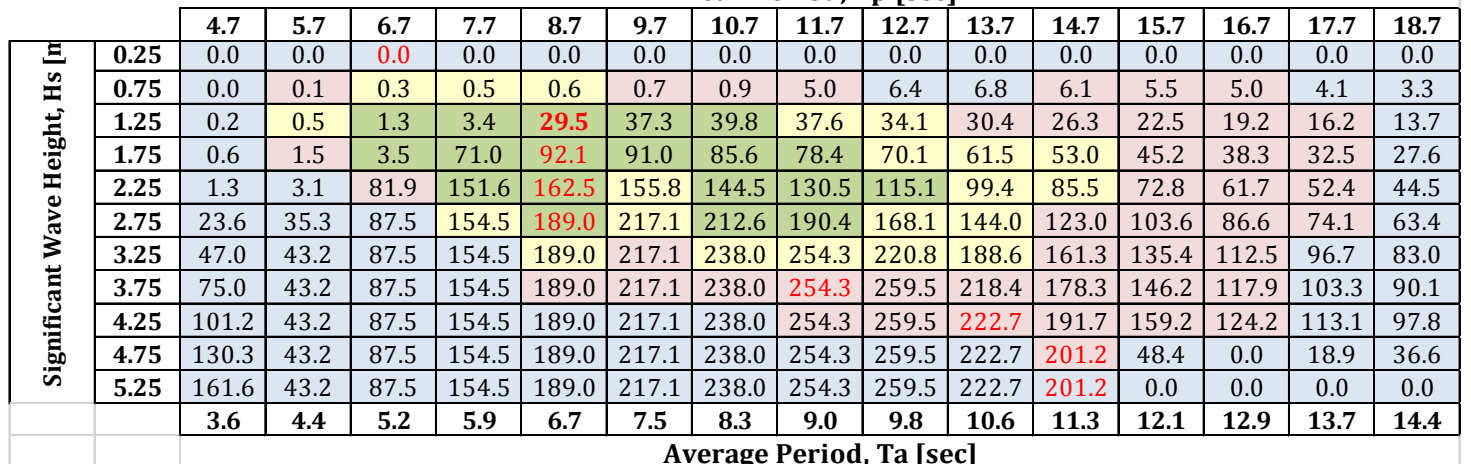

FIGURE 9. MECHANICAL POWER VS PEAK WAVE HEIGHT AND PEAK WAVE PERIOD. AAEP PRODUCED IS 91.7 KW.

Figure 10 shows the pneumatic to mechanical power for a VFD power rating of $373 \mathrm{~kW}$, a generator rating of $298 \mathrm{~kW}$, a vent pressure of $5380 \mathrm{~Pa}$, and a turbine tip radius of $1.88 \mathrm{~m}$. In Figure 10 the larger vent pressure allows for more energy to be captured by the BBDB. This combined with a VFD/generator power rating ratio of 1.25 results in more efficient conversion of pneumatic power to mechanical power to electrical power. Comparison of Figure 9 and Figure 10 corroborates the analysis of Figure 8: the VFD and generator power ratings limit the vent pressure and turbine tip radius. These limitations reduce the amount of power that can be efficiently converted from pneumatic power to mechanical power to electrical power.

Figure 11 shows the electrical power generated by the system of Figure 10 . It is interesting to see that the power decrements from the electricity generation equipment are not as large as those incurred by the pneumatic-tomechanical power conversion equipment. This indicates that the turbine size and vent pressure selection are critical parameters in the optimum PCC design.

Comparison of Figures $9 \& 10$ suggest that the PCC should be designed for the most energy dense sea states. Even though the PCC design in Figure 9 is better suited for the most probable wave (highlighted as bold-red number) the AAEP produced is lower than that of Figure 10, which was designed to be better suited for the more energy dense sea states. This finding is not altogether obvious seeing as one would think that the design should be focused on the most likely sea state. Doing so, however, could result in losing the opportunity to capture power from the most energy dense sea states.

Optimal Power Conversion Chain Specification

By following the procedure outlined above, the final design uses Starzmann's Rotor A at a tip radius of $1.88 \mathrm{~m}$, a vent pressure of $5380 \mathrm{~Pa}$, a VFD power rating of $373 \mathrm{~kW}$, and a generator rating of $298 \mathrm{~kW}$ (the design of Figure 11). The predicted AAEP for this design is $103.2 \mathrm{~kW}$. Hence the optimal PCC design for this device results in a rating of $373 \mathrm{~kW}$ with a capacity factor of 27.6 . Table 3 shows that $44.7 \%$ of the power losses in the PCC occur in the pneumatic-to-mechanical power conversion, while only $10.3 \%$ of the losses in the PCC are due to the mechanical-to-electrical power conversion. By selecting a more efficient turbine, the electric output of this device could be increased significantly.

TABLE 3. ANNUAL POWER FOR THE FINAL SELECTED DESIGN HIGHLIGHTING DECREMENT IN POWER AT EACH CONVERSION STEP.

\begin{tabular}{|r|c|c|c|}
\hline & AAP (kW) & \% Decrease & SAP (kW) \\
\hline Pneumatic Power & 208 & N/A & 831 \\
\hline Mechanical Power & 115 & 44.7 & 261 \\
\hline Electrical Power & 103 & 10.3 & 229 \\
\hline
\end{tabular}

\section{CONCLUSIONS}

A BBDB has been modeled in random waves. The dynamics of the device are treated spectrally. The pneumatic power is optimized through the selection of $R_{\text {load }}$ for each sea state. Statistical values derived from the spectral densities 
RMS Mechanical Power Data [kW], VentP = 5380 Pa, Rtip = 1.588 m, VFD Rating = 373 kW, Gen Rating 298 kW Peak Period, Tp [sec]

\begin{tabular}{|c|c|c|c|c|c|c|c|c|c|c|c|c|c|c|c|c|}
\hline & & 4.7 & 5.7 & 6.7 & 7.7 & 8.7 & 9.7 & 10.7 & 11.7 & 12.7 & 13.7 & 14.7 & 15.7 & 16.7 & 17.7 & 18.7 \\
\hline \multirow{11}{*}{ 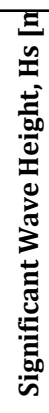 } & 0.25 & 0.0 & 0.0 & 0.0 & 0.0 & 0.0 & 0.0 & 0.0 & 0.0 & 0.0 & 0.0 & 0.0 & 0.0 & 0.0 & 0.0 & 0.0 \\
\hline & 0.75 & 0.0 & 0.1 & 0.2 & 0.4 & 0.5 & 0.6 & 0.6 & 0.6 & 1.3 & 3.3 & 3.4 & 3.4 & 3.4 & 2.6 & 2.0 \\
\hline & 1.25 & 0.2 & 0.5 & 1.1 & 1.8 & 13.5 & 27.2 & 32.5 & 35.1 & 32.2 & 29.1 & 25.2 & 21.7 & 18.6 & 15.6 & 13.2 \\
\hline & 1.75 & 0.5 & 1.3 & 3.0 & 49.3 & 80.8 & 86.5 & 82.9 & 77.0 & 69.0 & 60.8 & 52.5 & 44.9 & 38.2 & 32.3 & 27.4 \\
\hline & 2.25 & 1.1 & 2.7 & 40.8 & 138.9 & 156.7 & 153.0 & 142.9 & 130.5 & 116.3 & 101.5 & 87.3 & 74.4 & 62.8 & 53.4 & 45.4 \\
\hline & 2.75 & 7.6 & 4.9 & 131.7 & 228.7 & 243.8 & 233.4 & 215.6 & 194.3 & 170.9 & 148.1 & 127.4 & 108.5 & 91.8 & 78.0 & 66.2 \\
\hline & 3.25 & 33.4 & 50.7 & 225.3 & 307.9 & 346.1 & 327.2 & 296.7 & 265.8 & 234.5 & 200.9 & 171.4 & 144.4 & 120.7 & 103.3 & 88.4 \\
\hline & 3.75 & 60.4 & 130.7 & 225.3 & 307.9 & 365.7 & 408.8 & 389.7 & 343.9 & 296.7 & 252.5 & 216.0 & 182.5 & 151.7 & 130.3 & 111.8 \\
\hline & 4.25 & 94.7 & 153.3 & 225.3 & 307.9 & 365.7 & 408.8 & 443.8 & 419.2 & 364.7 & 303.9 & 248.3 & 198.9 & 160.4 & 140.2 & 123.2 \\
\hline & 4.75 & 124.3 & 153.3 & 225.3 & 307.9 & 365.7 & 408.8 & 443.8 & 456.1 & 398.8 & 309.5 & 255.9 & 209.0 & 171.9 & 148.7 & 128.5 \\
\hline & 5.25 & 156.4 & 153.3 & 225.3 & 307.9 & 365.7 & 408.8 & 443.8 & 456.1 & 401.7 & 332.0 & 278.5 & 192.7 & 103.6 & 120.4 & 125.7 \\
\hline & & 3.6 & 4.4 & 5.2 & 5.9 & 6.7 & 7.5 & 8.3 & 9.0 & 9.8 & 10.6 & 11.3 & 12.1 & 12.9 & 13.7 & 14.4 \\
\hline
\end{tabular}

FIGURE 10. MECHANICAL POWER VS PEAK WAVE HEIGHT AND PEAK WAVE PERIOD.

RMS Electrical Power Data [kW], VentP = 5380 Pa, Rtip = 1.588 m, VFD Rating = 373 kW, Gen Rating 298 kW

\begin{tabular}{|c|c|c|c|c|c|c|c|c|c|c|c|c|c|c|c|c|}
\hline & & \multicolumn{15}{|c|}{ Peak Period, Tp [sec] } \\
\hline & & 4.7 & 5.7 & 6.7 & 7.7 & 8.7 & 9.7 & 10.7 & 11.7 & 12.7 & 13.7 & 14.7 & 15.7 & 16.7 & 17.7 & 18.7 \\
\hline \multirow{13}{*}{ 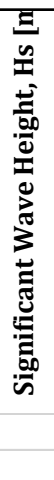 } & 0.25 & 0.0 & 0.0 & 0.0 & 0.0 & 0.0 & 0.0 & 0.0 & 0.0 & 0.0 & 0.0 & 0.0 & 0.0 & 0.0 & 0.0 & 0.0 \\
\hline & 0.75 & 0.0 & 0.0 & 0.0 & 0.0 & 0.0 & 0.0 & 0.0 & 0.0 & 0.0 & 0.2 & 0.2 & 0.2 & 0.2 & 0.1 & 0.1 \\
\hline & 1.25 & 0.0 & 0.0 & 0.0 & 0.0 & 4.3 & 14.7 & 19.0 & 21.3 & 18.8 & 16.2 & 13.0 & 10.1 & 7.6 & 5.7 & 4.2 \\
\hline & 1.75 & 0.0 & 0.0 & 0.2 & 35.2 & 68.4 & 75.1 & 70.9 & 64.1 & 55.3 & 46.6 & 38.3 & 30.8 & 24.1 & 18.9 & 14.8 \\
\hline & 2.25 & 0.0 & 0.1 & 26.6 & 128.3 & 145.6 & 142.0 & 132.2 & 120.0 & 106.1 & 91.4 & 76.1 & 61.2 & 48.8 & 39.2 & 31.4 \\
\hline & 2.75 & 1.6 & 0.6 & 121.3 & 215.7 & 229.0 & \begin{tabular}{|l|}
219.9 \\
\end{tabular} & 202.5 & 182.0 & 159.3 & 137.2 & 117.0 & 98.4 & 81.5 & 65.3 & 52.4 \\
\hline & 3.25 & 19.8 & 36.5 & 212.4 & 288.1 & 321.7 & 305.0 & 278.8 & 250.2 & 220.9 & 188.3 & 159.8 & 133.6 & 110.3 & 93.2 & 77.3 \\
\hline & 3.75 & 46.3 & 120.2 & 212.4 & 288.1 & 338.7 & 350.5 & 348.6 & 319.8 & 278.8 & 237.8 & 202.8 & \begin{tabular}{|l|}
170.4 \\
\end{tabular} & 140.7 & 119.9 & 101.5 \\
\hline & 4.25 & 84.7 & 142.3 & 212.4 & 288.1 & 338.7 & 350.5 & 344.8 & 350.3 & 337.8 & 284.8 & 233.4 & 186.4 & 149.2 & 129.5 & 112.8 \\
\hline & 4.75 & 114.0 & 142.3 & 212.4 & 288.1 & 338.7 & 350.5 & 344.8 & 339.7 & 349.9 & 289.4 & 241.1 & 196.0 & 160.2 & \begin{tabular}{|l|}
137.8 \\
\end{tabular} & 118.0 \\
\hline & 5.25 & 145.4 & 142.3 & 212.4 & 288.1 & 338.7 & 350.5 & 344.8 & 339.7 & 350.1 & 309.3 & \begin{tabular}{|l|}
261.9 \\
\end{tabular} & 180.4 & 93.5 & 110.1 & 115.3 \\
\hline & & 3.6 & 4.4 & 5.2 & 5.9 & 6.7 & 7.5 & \begin{tabular}{|l|}
8.3 \\
\end{tabular} & \begin{tabular}{|l|}
9.0 \\
\end{tabular} & \begin{tabular}{|l|}
9.8 \\
\end{tabular} & 10.6 & \begin{tabular}{|l|}
11.3 \\
\end{tabular} & 12.1 & 12.9 & 13.7 & 14.4 \\
\hline & & \multicolumn{15}{|c|}{ Average Period, Ta [sec] } \\
\hline
\end{tabular}

FIGURE 11. ELECTRICAL POWER VS PEAK WAVE HEIGHT AND PEAK WAVE PERIOD. AAEP PRODUCED IS 103.2 KW

Design studies using the PCC optimization procedure are based on the devices performance in the entire wave climate. The power generation equipment consists of a Wells turbine, an electric generator, and a Variable Frequency Drive (VFD). These studies have shown:

- The largest Average Annual Power (AAEP) prediction comes from using the Rotor A design of Starzmann [14].

- There exists an optimum turbine tip radius and vent pressure combination which will produce the largest AAEP, for a given VFD and generator combination.

- The AAEP, turbine tip radius, and vent pressure are all dependent upon the power ratings of the VFD and generator.

- Both the VFD and generator must be appropriately sized to achieve the maximum AAEP. The optimum ratio of VFD power rating/generator power rating is approximately 1.25 .
- The PCC should be designed for the most energy dense sea states, instead of the most probable, in order to maximize AAEP.

The interplay between turbine size, vent pressure, VFD power rating and generator power rating is complex. These AAEP predictions presented in this paper highlight some aspects of these relationships and that without consideration of each component in the entire system the PCC design could incur large power losses.

The optimization procedures, both for the $R_{\text {load }}$ as well as for the PCC components, could be improved. A fully stochastic model that accounted for the distribution of flow coefficients, and hence a distribution of mechanical conversion efficiency values, within a sea state would result in a more accurate, and likely lower, electrical power estimate. Further, optimization of $R_{\text {load }}$ based upon maximum electrical power output, as opposed to pneumatic power output, would result in a distinct profile from Figure 3. Work to 
understand these differences is currently underway.

\section{ACKNOWLEDGEMENTS}

The authors would like to acknowledge Dr. William C. Zierke (ARL PennState) for his contributions during the early stages of this work. Conversations with Dr. Thomas Carolus (Universität Siegen) were key to the incorporation of the VFD into this analysis.

This work was funded by the Department of Energies' Wind and Water Power Technologies Office. Sandia National Laboratories is a multiprogram laboratory managed and operated by Sandia Corporation, a wholly owned subsidiary of Lockheed Martin Corporation, for the U.S. Department of Energy's National Nuclear Security Administration under contract DE-AC0494AL85000.

\section{REFERENCES}

[1] Brito-Melo, A., Gato, L.M.C, Sarmento, A.J.N.A., 2001, "Analysis of Wells Turbine Design Parameters by Numerical Simulation of the OWC Performance", Ocean Engineering, 29, pp 14631477.

[2] D. V. Evans, "Wave-Power Absorption by Systems of Oscillating Surface Pressure Distributions," Journal of Fluid Mechanics, vol. 114, pp. 481-499, 1982.

[3] A. J. N. A. Sarmento and A. F. de O. Falcão, "Wave generation by an oscillating surfacepressure and its application in wave-energy extraction," Journal of Fluid Mechanics, vol. 150, pp. 467-485, 1985.

[4] Kurniawan, A, Hals, J, and Moan, Torgeir, "Modeling And Simulation of A Floating Oscillating Water Column," in Proceedings of the ASME 2011 30th International Conference on Ocean, Offshore and Arctic Engineering, Rotterdam, The Netherlands, 2011.

[5] D. Bull and E. Johnson, "Optimal Resistive Control Strategy for a Floating OWC Device," in Proceedings of the 11th European Wave and Tidal Energy Conference, Aalborg, Denmark, 2013.

[6] Lee, C.-H., Newman J.N., and Nielsen F.G., "Wave interactions with an oscillating water column," in Proceedings International Offshores and Polar Engineering Conference, Los Angeles, 1996

[30]Johannes Falnes, Ocean Waves and Oscillating Systems. New York: Cambridge University Press, 2002.

[7] Johannes Falnes, Ocean Waves and Oscillating Systems. New York: Cambridge University Press, 2002.

[8] Falcão, A.F.de O., Rodrigues, R.J.A., 2002, "Stochastic Modeling of OWC Wave Power Plant
Performance", Applied Ocean Research, 24, pp. 59-71.

[9] Curran, R., Stewart, T.P., Whittaker, T.J.T., 1997, “Design Synthesis of Oscillating Water Column Wave Energy Converters: Performance Matching", Journal of Power and Energy, 211, pp. 489-505.

[10] Falcão, A.F.de O., 2004, "Stochastic Modelling in Wave Power-Equiment Optimization: Maximum Energy Production Versus Maximum Profit", Ocean Engineering, 31, pp. 1407-1421.

[11] Setoguchi, T., Takao, M., 2005, "Current Status of Self Rectifying Air Turbines for Wave Energy Conversion", Energy Conversion and Management, 47, pp. 2382-2396.

[12] Gato, L. M. C., and Falcão, A. F. de 0., 1984, "On the Theory of the Wells Turbine," ASME Journal of Engineering for Gas Turbines and Power, 106(3), pp. 628-633.

[13] Raghunathan, S., 1995, "The Wells Air Turbine for Wave Energy Conversion," Prog. Aerospace Sci., 31, pp. 335-386.

[14] Starzmann, R., 2012, " Aero-Acoustic

Analysis of Wells Turbines for Ocean Wave Energy Conversion", VDI Verlag, Dusseldorf, Germany.

[15] Curran, R. Gato, L.M.C., 1997, "The energy conversion performance of several types of Wells turbine designs", J. of Power and Energy, 211, pp. 133-145.

[16] Falcão, A.F.de O., Justino, P.A.P, 1999, “OWC Wave Energy Devices with Air Flow Control", Ocean Engineering, 26, pp. 1275-1295.

[17]D. Bull and P. Jacob, "Methodology for creating nonaxisymmetric WECs to screen mooring designs using a Morison Equation approach," in OCEANS '12. "Harnessing the Power of the Ocean". Proceedings, Hampton Roads, VA, 2012, pp. 1 -9.

[18] Michel K. Ochi, Ocean Waves: The Stochastic Approach. Cambridge University Press, 1998.

[19] Subrata Chakrabarti, Hydrodynamics of Offshore Structures. WIT Press.

[20] Gato, L.M.C., Webster, M., 2001, “An experimental investigation into the effect of rotor blade sweep on the performance of the variablepitch Wells turbine", J. of Power and Energy, 215, pp. 611-622.

[21] Burt, C.M., Piao, X., Gaudi, F., Busch, B. Taufik, N.F.N., 2008, "Electric Motor Efficiency under Variable Frequencies and Loads".

[22] US Department of Energy, Advanced Manufacturing Office, 2012, "Adjustable Speed Drive Part-Load Efficiency". 